\title{
Nutritional Neuroscience \\ The Effect of Breakfast vs. No Breakfast on Brain Activity in Adolescents when Performing Cognitive Tasks, as Assessed by fMRI \\ --Manuscript Draft--
}

\begin{tabular}{|c|c|}
\hline Manuscript Number: & NNS358R2 \\
\hline Full Title: & $\begin{array}{l}\text { The Effect of Breakfast vs. No Breakfast on Brain Activity in Adolescents when } \\
\text { Performing Cognitive Tasks, as Assessed by fMRI }\end{array}$ \\
\hline Article Type: & Original Research Paper \\
\hline Keywords: & Cognitive Function; Breakfast; fMRI; nutrition \\
\hline Corresponding Author: & $\begin{array}{l}\text { Jonathan Fulford, PhD } \\
\text { University of Exeter } \\
\text { Exeter, UNITED KINGDOM }\end{array}$ \\
\hline \multicolumn{2}{|l|}{$\begin{array}{l}\text { Corresponding Author Secondary } \\
\text { Information: }\end{array}$} \\
\hline Corresponding Author's Institution: & University of Exeter \\
\hline \multicolumn{2}{|l|}{$\begin{array}{l}\text { Corresponding Author's Secondary } \\
\text { Institution: }\end{array}$} \\
\hline First Author: & Jonathan Fulford, PhD \\
\hline \multicolumn{2}{|l|}{ First Author Secondary Information: } \\
\hline \multirow[t]{3}{*}{ Order of Authors: } & Jonathan Fulford, PhD \\
\hline & Joanna L Varley-Campbell, MSc \\
\hline & Craig A Williams, PhD \\
\hline \multicolumn{2}{|c|}{ Order of Authors Secondary Information: } \\
\hline Abstract: & $\begin{array}{l}\text { Objectives } \\
\text { The study examined the feasibility of utilizing functional magnetic resonance imaging } \\
\text { (fMRI) with a group of adolescent boys and girls to assess modifications in cognitive } \\
\text { function, dependent upon the nutritional state of the participants. } \\
\text { Methods } \\
\text { Twenty children aged } 12 \text { to } 14 \text { years, completed two cognitive trials, in a randomized } \\
\text { counter balanced order, one in a fasted condition, one after consuming breakfast, } \\
\text { during which continuous fMRI data was acquired. } \\
\text { Results } \\
\text { Although no statistically significant }(P>0.05) \text { improvement in task performance was } \\
\text { determined, significantly higher activation was recorded in the frontal, pre-motor and } \\
\text { primary visual cortex areas in the breakfast trial relative to the fasted. } \\
\text { Discussion } \\
\text { Such a finding may have important implications in the examination of the role of diet, } \\
\text { and specifically breakfast, in determining children's performance within the school } \\
\text { environment. }\end{array}$ \\
\hline
\end{tabular}




\title{
Nutritional Neuroscience ('the Journal')
}

\section{ASSIGNMENT OF COPYRIGHT}

In order for W.S Maney \& Son Ltd, trading as Maney Publishing ('the Publisher'), to ensure the widest possible dissemination and protection of articles published in the Journal, we request authors to assign worldwide copyright in print, digital and other media in their article, including abstracts, to W. S. Maney \& Son Ltd. This enables the Publisher to ensure maximum international copyright protection against infringement, and to disseminate your article, and the Journal, to the widest possible worldwide readership. Should the article be rejected from the Journal for any reason, all rights assigned within this document revert back to the author(s) of the article.

Please read the explanatory notes of this agreement on the following page.

1. In consideration of the undertaking set out in paragraph 2, the author(s) as beneficial owner(s) hereby assign(s) to W. S. Maney \& Son Ltd all rights, title and interest in the copyright throughout the world in the article named below (which shall be taken to include any or all supplementary material associated with the article ${ }^{\star}$ ) for the full legal term of copyright.

\section{Article title: The Effect of Breakfast $v$ No Breakfast on Brain Activity in Adolescents when Performing Cognitive Tasks, as Assessed by fMRI Name(s) of Author(s): Jonathan Fulford \\ Manuscript no./ref. (if known) NNS358}

\begin{abstract}
If this paper is sponsored for Open Access by your grant funders, please follow the MORE OpenChoice route by signing and returning this copyright assignment to the address below, and find details of the policy and how to make payment at www.maneyonline.com/openaccess.
\end{abstract}

So that there should be no doubt, it is understood and agreed that this assignment includes the right to publish or adapt (subject to paragraphs 3 and 4) the material in the article for use in conjunction with computer systems, including networks. The article may be published in printed, CD-ROM, microfiche, online, or other machine-readable form, or in any other format or medium (electronic or otherwise) approved by W. S. Maney \& Son Ltd; and subject to data mining.

2. Maney Publishing, as the Journal's publisher, hereby undertakes to prepare for publication and publish in the Journal, the Article named in paragraph 1.

3. The editor of the Journal, and the Publisher, are empowered to make such editorial changes as may be necessary to make the Article suitable for publication. Every effort will be made to consult the Author(s) if substantive changes are required.

4. The author(s) hereby assert(s) their moral rights under the terms of the Copyright Designs and Patents Act 1988 to be identified as the Author(s) of the Article.

5. The author(s) warrant(s) that the article is the author(s)' original work, has not been published before, either in part or whole, and is not currently under consideration for publication elsewhere. The author(s) also warrant(s) that (a) the article contains no libellous or unlawful statements, (b) it in no way infringes the rights of others (including the holders of copyright in material used within the article), (c) that permission has been obtained to reproduce any material or illustrations for which they do not hold copyright, and that (d) the author(s), as the owners of the copyright, is (are) entitled to make the assignment set out in this agreement. The author(s) hereby indemnifies/indemnify the Publisher against any claims for breach of the warranties given above. 
6. In cases where the article is a translation of a previously published article, the author(s) warrant(s) that full permission has been obtained to carry out and publish the translation of the article from its original language, and that it in no way infringes the rights of others (including the holders of copyright in material used within the original Article).

7. The author(s) warrant(s) that the article contains no plagiarised material and agree(s) that the article may be checked for plagiarism and other ethical questions (including checks using automated software packages). The Publisher reserves the right to withdraw or retract any article for which, in its reasonable opinion, valid concerns exist over the originality of the article, or its compliance with the Journal's ethical policy. Maney's plagiarism and ethical policy may be read in full at www.maneyonline.com/page/authors/publishingethics-general.

*If the author(s) cannot assign copyright for any or all the supplementary material, the clause in parentheses should be struck out and a licence to publish provided for this material. If copyright is held by a third party, permission to reproduce this material must be obtained from the copyright holder as laid out in paragraph 5 of this form and submitted to the publisher.

\section{Copyright Assignment}

I confirm that all the co-authors, named above in 1, know that the article has been submitted to the Journal. I hereby sign this Assignment of Copyright with the full knowledge and agreement of all authors.

Signed: J Fulford Date: $21 / 11 / 14$

Printed name: Jonathan Fulford

Please note: it is essential for publication that Maney Publishing receive this signed Assignment of Copyright form. Without it, we will be unable to proceed to publication.

Please complete all specified fields and return this signed form to the Production Editor of the Journal.

Production Editor, NNS, for Maney Publishing

nns@maneypublishing.com; fax: +44 (0) 2074517307

1 Carlton House Terrace, London SW1Y 5AF, UK 


\section{ASSIGNMENT OF COPYRIGHT: EXPLANATORY NOTES}

1. The Journal's policy is to acquire copyright for all contributions for the following reasons:

a. ownership of copyright by a central organisation helps to ensure maximum international protection against infringement;

b. requests for permission to reproduce articles in books, course packs or for library loan can be handled efficiently and with sensitivity to changes in international copyright law and to the general desirability of encouraging the widest dissemination of knowledge. At the same time, this relieves editors and societies of a time-consuming and costly administrative burden;

c. the demand for research literature to be delivered in machine-readable form, on-line or on CD-ROM or downloaded on a file server, can be met efficiently, with proper safeguards for authors, editors and journal owners.

2. As the information market changes, there are opportunities to reach both individual readers and institutions (e.g. companies, schools and public libraries) that are unlikely to subscribe to the Journal. This involves working with other organisations to publish online services or CD-ROM, or to deliver copies of individual articles. It also involves registering the Journal with the Copyright Licensing Agency in the UK and the Copyright Clearance Center in the USA, which offer centralised licensing arrangements for photocopying. Income received from all of these sources will be used to further the interests of the Journal.

3. As a consequence of the above, your article will be published in electronic, machine-readable form, and normally printed, in the Journal, and may be stored electronically either by Maney or by a duly licensed third party for delivery as an individual article copy or as part of a larger collection of articles, from a range of journals to meet the specific requirements of a particular market. Assignment of copyright signifies agreement to the Journal making such arrangements.

4. It may be that the author is not able to make the assignment solely by him- or herself:

a. If it is appropriate, the author's employer may sign this agreement. The employer may reserve the right to use the article for internal or promotion purposes (by indicating on this agreement), and reserve all rights other than copyright.

b. If the author is a UK Government employee, TSO will grant a non-exclusive licence to publish the article in the Journal in any medium or form provided that Crown Copyright and user rights (including patent rights) are reserved.

c. If the author is a US Government employee and the work was done in that capacity, the assignment applies only to the extent allowed by US law.

5. Under the UK's Copyright Design and Patents Act 1988, the author has the moral right to be identified as the author whenever and wherever the article is published. He or she also has the right to object to derogatory treatment or distortion of the work. The Journal encourages assertion of this right, as it represents best publishing practice and provides an important safeguard for all authors. Clause 4 ensures that moral rights are asserted, as required by the Act.

6. Authors who wish to reproduce material from previously published sources or where the copyright is owned by a third party, such as sections of text, tables or images, must obtain written permission from the copyright holder and the author(s)/artist(s) of the original material. In the case of translations, the author(s) must obtain written permission from the copyright holder of their original article upon which the translation is based. Copyright is required for use in all formats (including digital), in perpetuity and in all geographical regions world-wide (and in colour for illustrations where relevant). For more information please see www.maneyonline.com/page/authors/copyrightandpermissions.

7. The Journal will not withhold permission from the author to use the content of his or her own article elsewhere after publication in the Journal, provided acknowledgement is given to the Journal as the original source of publication. Further permission is required for republication to be made in a commercial product and authors should contact permissions@maneypublishing.com with their request. Permission is never unreasonably withheld.

8. The corresponding author shall receive a PDF file (Eprint) of the final, published, version of the article, which may be forwarded and shared with all co-authors, and other research associates, but it cannot be archived or put on a personal or institutional website, or in a subject based open access repository. No commercial use shall be made of the article, or the PDF file, without Maney's prior, written permission. 
9. Authors may:

(a) put a copy of their un-refereed, unedited article (i.e. before peer-review - sometimes called a pre-print), on their personal or institutional website, or in an institutional, or subject based repository; and

(b) put a copy of their final accepted version of the article (i.e. after peer-review but without Maney editing and typesetting - sometimes called a post-print) on a non-commercial institutional repository subject to an embargo period of twelve months from the date of publication, as long as (i) full acknowledgement is made of the Journal issue in which the article is published, when this information is available; (ii) there is a link to the published online version of the article on Maney's chosen online hosting platform, to the Journal, and the Publisher's website at www.maneyonline.com, and any other information specified in the copyright transfer statement; and (iii) no commercial use is made of the article. A pre-print of an article should be replaced by a post-print once the article has been accepted for publication. (In the case of translations of original articles, this is subject to the permissions given by the copyright holder of the original article). For more information please visit www.maneyonline.com/page/authors/copyrightandpermissions or email permissions@maneypublishing.com

10. Exceptions may be made to this policy in the following circumstances:

Sponsored open access papers (published as MORE OpenChoice papers) can be distributed under the terms of one of three different Creative Commons licences:

1. CC-BY: Creative Commons Attribution Licence 3.0

This licence permits others to re-use, reproduce, re-distribute and/or build upon your work, including for commercial purposes, providing they acknowledge you as author, and attribute original publication to the journal.

Articles using this licence will carry the following copyright line:

(C) W. S. Maney \& Son Ltd 2014

MORE OpenChoice articles are open access and distributed under the terms of the Creative Commons Attribution Licence 3.0

2. CC-BY-NC: Creative Commons Attribution Non-Commercial Licence 3.0

This licence permits others to re-use, reproduce, re-distribute or build upon your work providing they acknowledge you as author, and attribute original publication to the journal, and that reuse is restricted to noncommercial purposes, i.e. research or educational use.

For this licence, the copyright line will reads as follows:

(C) W. S. Maney \& Son Ltd 2014

MORE OpenChoice articles are open access and distributed under the terms of the Creative Commons Attribution Non-Commercial Licence 3.0

3. CC-BY-NC-ND: Creative Commons Attribution Non-Commercial No Derivs Licence 3.0 This licence permits others to re-distribute your work providing they acknowledge you as author, and attribute original publication to the journal. Your work cannot be altered, transformed or built upon, and use is restricted to non-commercial purposes, i.e. research or educational use.

Articles using this licence will carry the copyright line:

(C) W. S. Maney \& Son Ltd 2014

MORE OpenChoice articles are open access and distributed under the terms of the Creative Commons Attribution Non-Commercial No Derivs Licence 3.0

Unless otherwise specified, the Creative Commons Attribution Non-Commercial Licence 3.0 (CC-BY-NC) will be used. 
Reviewer \#1: The revisions to the manuscript address many of the original comments, although somewhat minimally in some cases. For example, whilst the division of errors into misses and false positives is good, it seems inconsistent that some of this data is analysed with t-tests whilst other parts of the error are treated with rank tests. I would like to encourage a consistent statistical approach, preferably using the binomial test as commented previously, especially since the normality of a distribution is difficult to assess reliably in small samples. However, that said I think that the impact on the results will be minimal and the overall pattern would not change. Hence I will leave it to the authors and the editor to decide on the preferred approach here and would not object to publication in the current form.

We have redone the statistical analysis of the different aspects of the cognitive test performance using a repeated measures analysis using mixed models as originally suggested by the reviewer. The methods have subsequently been modified to reflect this.

One other minor change: on page 10, the sub-heading should read "fMRI analyses" and not 'analyzes'.

Changed as suggested. 
The Effect of Breakfast vs. No Breakfast on Brain Activity in Adolescents when Performing Cognitive Tasks, as Assessed by fMRI

Jonathan Fulford $^{1}$, Joanna L Varley-Campbell ${ }^{2}$ and Craig A Williams ${ }^{2}$

${ }^{1}$ Exeter NIHR Clinical Research Facility, University of Exeter Medical School, University of Exeter, UK

${ }^{2}$ Children's Health and Exercise Research Centre, Sport and Health Sciences, College of Life and Environmental Sciences, University of Exeter, UK

\section{Conflict-of-Interest}

A grant was received of $£ 18,678.08$ from Kellogg Marketing \& Sales Company (UK) Ltd to cover MRI scanning costs. Otherwise the research was conducted with the support of internal institutional funds and the authors received no other direct or indirect support, with no further competing interests.

\section{Acknowledgements}

We are grateful to the pupils and teachers of St James School for their participation in this project. 


\section{Abstract}

\section{Objectives}

The study examined the feasibility of utilizing functional magnetic resonance imaging (fMRI) with a group of adolescent boys and girls to assess modifications in cognitive function, dependent upon the nutritional state of the participants.

\section{Methods}

Twenty children aged 12 to 14 years, completed two cognitive trials, in a randomized counter balanced order, one in a fasted condition, one after consuming breakfast, during which continuous fMRI data was acquired.

\section{Results}

Although no statistically significant $(\mathrm{P}>0.05)$ improvement in task performance was determined, significantly higher activation was recorded in the frontal, pre-motor and primary visual cortex areas in the breakfast trial relative to the fasted.

\section{Discussion}

Such a finding may have important implications in the examination of the role of diet, and specifically breakfast, in determining children's performance within the school environment.

Keywords: Cognitive function; Breakfast; fMRI; Nutrition 


\section{Introduction}

The interaction between diet and cognitive function is an area that has received increasing attention over the last decade. In particular, the impact of diet on performance in children and its role within the school environment has been of interest ${ }^{1}$. The most readily controlled aspect of children's diet and potentially the one that has the greatest influence on their performance in school is breakfast. As a result, a number of studies have been specifically aimed at assessing the acute role breakfast has to play in dictating cognitive performance in $\operatorname{school}^{2-6}$. These have generally revealed a detrimental effect in terms of attention, concentration and memory as a result of missing breakfast with an associated increase in cognitive performance when nutritional requirements are fully met. Likewise, longer term studies have reported regular breakfast consumption results in significantly improved IQ scores $^{7}$ and structural magnetic resonance imaging (MRI) scans have provided some evidence that the long term choice of breakfast leads to alterations in brain gray matter volume with an associated modification in cognitive ability ${ }^{8}$.

Functional magnetic resonance imaging (fMRI) is a technique that is widely utilized in a range of scientific disciplines for the assessment of brain activity ${ }^{9}$. The method relies on detecting changes in local blood flow and oxygen content in those areas within the brain which are active when performing specific tasks. It subsequently provides an ideal tool for examining the degree of brain involvement when faced with cognitive tests and how this may be modified by external factors such as diet.

At present, although there is an extensive body of literature examining fMRI responses to cognitive tests, including a number examining the longer term of effects of dietary supplements ${ }^{10}$, very little work has been associated with assessing the acute impact of diet, 
and specifically breakfast on cognitive performance. Of those fMRI studies that do exist ${ }^{11-12}$, the focus has been on adult participants rather than any assessments of the cognitive sensitivity of adolescents to dietary state, although they have shown that for participants conducting N-back tasks, greater activity was observed in the medial prefrontal cortex following a nutritionally balanced breakfast when compared to either no breakfast or only sugar. Although fMRI protocols have been conducted on adolescent participants, these are small in number relative to adult studies ${ }^{13}$ and have mainly focused on more passive tasks, such as examining responses to visual stimuli, although some have been used to examine cognitive responses ${ }^{14-15}$. Such an imbalance in relative studies has a number of potential causes. Availability of participants, ethical concerns regarding adolescent populations and potentially reduced compliance to the tasks performed with younger individuals are all possible factors. However, in many respects, an understanding of the functioning of the paediatric brain has greater long-term implications.

Therefore, the aim of the current study was to assess the potential of using fMRI to measure brain activity associated with cognitive tasks in adolescent individuals and examine the sensitivity to acute dietary state by measuring fMRI response differences between when they were satiated or fasted.

\section{Methods}

The study was conducted in accordance with the guidelines of the Declaration of Helsinki, the British Association of Sport and Exercise Sciences (BASES) and the British Education Research Association (BERA) and all procedures were approved by the institutional ethics committee. School based consent was firstly obtained from the head teacher and thereafter written informed consent and a completed health questionnaire were obtained from the 
parents together with a signed assent from all the participants. Exclusion criteria consisted of the following; participants with any known food allergies, participants with clinically diagnosed learning difficulties, or participants with known counter-indications for MRI scanning e.g. claustrophobia.

\section{Participants}

Twenty one adolescent male $(n=10)$ and female $(n=11)$ volunteers (age 12-14 y) were recruited for the study drawn from local schools with whom studies have previously been undertaken. Stature, body mass and sitting stature were measured. Stature and sitting stature were measured using a Holtain stadiometer (Holtain Ltd, Crymmych, UK ) accurate to 0.1 $\mathrm{cm}$ and body mass accurate to $0.1 \mathrm{~kg}$ using a Seca digital scale (Seca, Hamburg, Germany). The average age, stature, sitting stature and body mass of the group of 20 that undertook the fMRI protocol were $13.3 \pm 0.7 \mathrm{y}, 159.7 \pm 6.6 \mathrm{~cm}, 82.4 \pm 4.8 \mathrm{~cm}$ and $50.6 \pm 8.7 \mathrm{~kg}$ respectively.

\section{Study Design}

All participants initially visited the centre to practise performing all of the cognitive tasks, both outside of the scanner environment, so that they were fully conversant with the requirements of each test, as well as within a to-scale mock MRI scanner to ensure they were comfortable within the confined space. During this visit all participants also visited the actual scanner so the entire environment was familiar, with the aim of minimizing stress during the testing days and to reduce any differences in responses between the trial days as a result of anxiety. The familiarisation session preceded the actual trials by approximately seven days. 
For the testing proper, participants visited the centre on two occasions, when they performed the full cognitive testing procedure within the MRI scanner. The study comprised a randomized cross over design, and was counter balanced, with an equal number of participants having breakfast prior to or after the scanning session on their first visit, with the breakfast order reversed for their second trial visit. For each visit, participants arrived at the centre having had an overnight fast from $10 \mathrm{pm}$ the previous night with them blind to which breakfast regime they would be allocated to on their first visit. The trials were scheduled approximately seven days apart.

Participants arrived in pairs, one of whom was offered only water to ensure adequate hydration levels, while the other was provided with a controlled breakfast. The breakfast consisted of a $40 \mathrm{~g}$ cereal serving of wheat biscuits with a sugar frosting together with 125 $\mathrm{mL}$ of semi-skimmed milk, resulting in a total calorific load of $207 \mathrm{kcal}$ (carbohydrates $35 \mathrm{~g}$ of which starch comprised $22 \mathrm{~g}$ and sugar $13 \mathrm{~g}$, fat $3 \mathrm{~g}$ of which $1.5 \mathrm{~g}$ was saturated, protein 9 $\mathrm{g}$, fibre $3.5 \mathrm{~g}$ ). Participants were given 15 minutes to consume the breakfast. The participant who was to be scanned without consuming breakfast started the scanning session approximately 30 minutes after arrival, at 9am, equivalent to the typical starting time of the school day. On completion of the testing procedure they were subsequently offered breakfast, without limits on consumption levels. For the participant who was given breakfast prior to the scanning session, scanning took place approximately $1.5 \mathrm{hr}$ after arrival, a time estimated to be equivalent to the typical time between breakfast consumption and the start of the school day. During the interval between breakfast consumption and scanning, the participant waited within the MR centre, during which time they were given access to reading material and other entertainment in order to keep them engaged. Although it was not possible to ensure exactly the same activities were undertaken for each visit, any possible confounding aspects on 
subsequent cognitive task performance were attempted to be minimized by providing the same entertainment material for each visit and ensuring that the presence of food images within the literature supplied was minimised.

\section{fMRI protocol}

The stimuli were presented to participants in a $1.5 \mathrm{~T}$ Philips Gyroscan scanner with an eight element head coil. Within the head coil was mounted a mirror assembly, such that with their head within the coil, participants were able to see a screen at the end of the scanner bed onto which the cognitive tasks were projected. Scanning consisted of initial surveys to determine participant position and a reference scan for coil calibration purposes, with the procedure taking approximately two minutes. The assessment of brain activity during cognitive tasks involved using a standard single shot echo-planar dynamic imaging (EPI) sequence as routinely used for fMRI studies $(\mathrm{TR}=3 \mathrm{~s}, \mathrm{TE}=45 \mathrm{~ms}$, resolution $2.5 \times 2.5 \times 3.5 \mathrm{~mm}, 39$ contiguous transverse-oblique slices, scans field of view 230 × 230 mm, 64 x 64 within-plane matrix). Each section of the cognitive tasks required running separate dynamic EPI scans, with the participants given the opportunity to move and get comfortable between each set. This procedure was then followed by a high resolution dynamic scan T1-weighted anatomical image with a resolution of $0.9 \times 0.9 \times 0.9 \mathrm{~mm}$, taking approximately 3.5 minutes

\section{Cognitive Tasks}

The chosen tests were designed to be independent of knowledge, training, practice or educational level, particularly in terms of language or mathematical ability. Instead, they were selected to specifically challenge attributes associated with attention and memory. Other restrictions were imposed by the requirement that the testing took place within the scanner environment, limiting the range of viable participant response options. To ensure ease of 
response therefore, tasks were selected that required the pressing of a single button of MRI compatible response boxes held in each hand. All cognitive tests were presented in E-Prime version 2 (Psychology Software Tools Inc, Sharpsburg, USA). All participant responses were recorded to allow for an assessment of accuracy and reaction times and participants were instructed to respond as quickly but as accurately as possible. The first task selected was a simple choice reaction time where participants responded as quickly as possible when presented with an arrow which was either pointing towards the left or the right, in response to which they were required to press the button in the corresponding hand ${ }^{16}$. Three sets of the task were run, each of which consisted of the presentation of 45 arrow stimuli. Arrows were presented for $400 \mathrm{~ms}$ after which a blank screen was shown for a variable duration between 2000 and $7000 \mathrm{~ms}$. The subsequent tasks were N-Back tests that required the participants to identify occurrences of letters being the same as the previous one (1-back), or two previous $(2 \text {-back })^{17}$. Letters were presented for $1000 \mathrm{~ms}$ followed by a blank screen for $750 \mathrm{~ms}$. Three sets of both 1 and 2-back trials were run, each of which consisted of the presentation of 64 consecutive letters. The choice reaction time examines general alertness and motor speed whereas the N-back task specifically assesses working memory function as a result of participants being required to maintain and update a dynamically changing set of features.

\section{Data pre-processing and analysis}

Functional images were analyzed using SPM8 software (The Wellcome Department of Cognitive Neurology, University College London); a suite of MATLAB functions and subroutines with some externally compiled C routines. Pre-processing included slice time correction, spatial processing to correct for head movement and size, and warping to the Montreal Neurological Institute template (MNI305). Images were then convolved with a 3D Gaussian filter with an $8 \mathrm{~mm}$ full-width-at-half-maximum (FWHM). The fMRI data was 
analyzed based on massunivariate (voxel-by-voxel) testing within the general linear model framework over the whole brain, treating each participant separately and constructing individual maps comparing the differences in response between the two visits. Group analysis was subsequently undertaken combining the individual responses, with significant brain activation defined as arising within a region when the differences in signal intensity between visits gave rise to a P-value $<0.001$ after no corrections had been made for multiple comparisons and the cluster size of the activated region was equal or greater than 10 voxels.

When examining cognitive test scores, response times were filtered such that no anticipatory responses, defined as reaction times less than $10 \mathrm{~ms}$, were registered. A maximum response time (2400 ms) was also implemented to prevent mis-asignment of responses. For the decision making task, performance was assessed via the response time and the number of incorrect responses. For the N-back tests, performance was assessed via response time, the number of times participants did not identify matching letters when they arose (no-response) and the number of times they incorrectly considered that a matching pair had occurred (false positive). In all cases group means \pm standard deviation were determined. To examine any significant changes in reaction times and in the frequency of incorrect responses, no$\underline{\text { responses and false positives in the respective tests, data were assessed using a repeated }}$ measures analysis using mixed models. To assess whether the results were normally distributed Shapiro-Wilk tests were run on all data. In the event of normal distributions, as there were no gender response differences, all participants were grouped and assessed using Student's paired sample t-test. For non-normally distributed data Wilcoxon signed rank sum tests were utilized. To examine any possible trade-off between reaction times and response accuracy, Pearson correlation coefficients were determined for the differences in reaction 
times and accuracy between fasted and after breakfast conditions for all individual cognitive tests, with significance defined as $\mathrm{P}<0.05$.

\section{Results}

One female, although initially recruited and familiarised to the test protocol decided not to continue and withdrew from the study. Of the remaining 20 participants, 19 contributed to the statistical assessment of the decision-reaction task performance and 18 to the N-back task with 1 and 2 participants respectively removed due to poor task compliance. For the fMRI data, from the subset of participants whose responses had been assessed, the results from 16 participants were examined for both tests, the remaining data sets having been discarded due to excessive movement.

\section{Cognitive Task Performance}

For the decision making task, there were no significant differences between reaction time (Fasted: $493.3 \pm 51.0 \mathrm{~ms}$, After breakfast: $493.0 \pm 76.0 \mathrm{~ms}$ ), or the number of incorrect

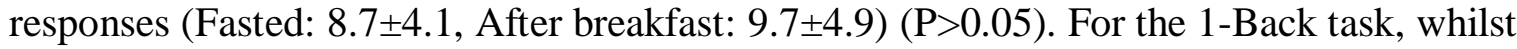
the reaction times were faster following breakfast (Fasted: $548.6 \pm 88.2 \mathrm{~ms}$, After breakfast: $543.0 \pm 89.0 \mathrm{~ms}$ ), neither it or the number of incidences of no-response (Fasted: $2.8 \pm 3.5$, After breakfast: $2.1 \pm 2.3$ ) or false positives (Fasted: 1.5 \pm 1.9 , After breakfast:1.6 \pm 1.8 ) were statistically significant $(\mathrm{P}>0.05)$. Likewise, for the 2-Back task although the reaction time was faster (Fasted: $617.0 .6 \pm 100.8 \mathrm{~ms}$, After breakfast: $611.6 \pm 111.6 \mathrm{~ms}$ ), and the number of incidences of no-response (Fasted: 8.6 \pm 3.6 , After breakfast: $8.3 \pm 1.2$ ) and the number of errors was lower (Fasted: 2.8 \pm 3.6 , After breakfast: $1.5 \pm 1.2$ ) following breakfast, no significant differences were found $(\mathrm{P}>0.05)$. 
No significant correlations $(\mathrm{P}>0.05)$ were found between changes in reaction times and response accuracy between fasted and after breakfast conditions for any of the cognitive tests.

\section{fMRI analyseszes}

Figure 1 illustrates the areas of activation which were significantly higher in the breakfast condition compared to the fasted state $(\mathrm{P}<0.001)$ for the decision reaction task for the 16 participants included in the data analysis. Increased activation was seen in Brodmann area 6, in the frontal/pre-motor area, a region associated with planned motor actions. No areas of significantly increased activation were seen in the fasted state relative to the breakfast condition. In Figure 2 the fMRI areas of increased activation for the breakfast condition relative to fasted state are shown for the $\mathrm{N}$-back 1 and 2 tasks $(\mathrm{P}<0.001)$. Two main areas of activation were observed, the first of which was the cuneus (Brodmann area 17) the site of basic visual processing. The other was Brodmann area 45 in the frontal cortex which is associated with semantic decision tasks such as that associated with the examination of the composition of words and letters. No areas of significantly increased activation were seen in the fasted state relative to the breakfast condition.

\section{Discussion}

The study examined the feasibility of utilizing fMRI with a group of adolescent boys and girls to assess modifications in cognitive function, dependent upon the nutritional state of the participants. By doing so, the aim was to determine whether certain areas of the brain associated with cognitive processing and attention were more active when the individual was satiated, compared to fasted. 
No significant modifications were seen in performance in the cognitive tasks as a result of dietary state within the present study. This is in contrast to recent studies by Cooper and colleagues $^{18-19}$ where breakfast consumption did significantly improve cognitive function (on some accuracy parameters but not response time) based on a visual search test, the Stroop test and the Sternberg paradigm in an adolescent group of students. However, the lack of significant differences seen in the present study may simply be due to an under powering of the experiment in terms of cognitive task performance, as our post hoc calculations estimate approximately $55-70$ participants would be needed to establish statistically significant differences, a figure in line with the numbers tested by Cooper et al ${ }^{18-19}$. However, given that the nature of the current study was an exploratory assessment of differences which could be detected via fMRI methods the recruitment levels selected were based upon the typical sensitivity of this technique. Any under powering of the experiment from the perspective of detecting differences in cognitive test performance scores was not a primary consideration.

The areas of increased activation following the analysis of the fMRI data seen in the breakfast trial relative to the fasted are generally indicative of a state of increased participant attentiveness and are in line with what might be anticipated given the nature of the trials. Brodmann area 6 , in the frontal/pre-motor area, is a region associated with planned motor actions and has previously been associated with choice reaction tests ${ }^{20-21}$. Likewise, for the $\mathrm{N}$-back tasks the areas of increased relative activation following breakfast consumption link closely with the demands of the task. The cuneus (Brodmann area 17) is the site of basic visual processing and Brodmann area 45, in the frontal cortex, is associated with a number of demands attributed to the N-back task, such as the selection and assessment of the stimuli presented and held in short and long term memory, and has previously been reported when undertaking the N-back protocol ${ }^{22}$. 
The underlying cause of the increased cerebral activity seen following the breakfast consumption may arise simply from an increased metabolic availability of glucose. Indeed, the suggestion that alterations in blood glucose levels lead to modifications in cognitive efficiency are long standing ${ }^{23}$, supported by a number of studies reporting improvements in a range of cognitive performance measures following the administration of a glucose drink ${ }^{24-27}$. However, other studies have highlighted differences in acute cognitive performances dependent upon the nutritional content of food, rather than purely the glucose $\operatorname{load}^{28}$. In addition, work by Akitsuki et $a l^{11}$ has reported greater brain activation, as assessed by fMRI, when undertaking cognitive tasks following a nutritionally balanced breakfast than sugar alone, suggesting the quality of the breakfast has an impact on subsequent cognitive performance.

fMRI protocols with an adolescent population have a number of intrinsic problems, either not present or reduced in an adult one. Their ability to maintain concentration and focus, and as a consequence their ability to stay still during the course of the experiments, appears limited. We have aimed to minimize these effects by selecting cognitive tasks that require continual feedback on the part of the participant and breaking the tasks up into short periods (approximately 4 minutes) with intervals in between. In addition, extensive practice was undertaken prior to the testing proper so that participants were familiar with the environment and the demands of the testing procedure. Even so, it was still necessary to remove a certain number of participants, approximately $20 \%$, from analysis for each of the tasks, due to either inattention, resulting in very poor task performance, or else excess movement. However, these numbers remain within the range of those that can be accommodated by appropriate 
levels of recruitment and illustrate the feasibility of undertaken cognitive fMRI testing with such a population.

In conclusion, the main finding of the study was that significantly increased fMRI signal was observed within Brodmann areas 6, 17 and 45 when performing cognitive tests in adolescents after breakfast consumption of $209 \mathrm{kcal}$ compared to the fasted state, although no associated increases in test performance were detected. Such a finding may have important implications in the examination of the role of diet in determining performance of children within the school environment 


\section{References}

1. Benton D. The influence of children's diet on their cognition and behaviour. Eur J Nutr. 2008;47(Suppl 3):25-37.

2. Benton D, Jarvis M. The role of breakfast and a mid-morning snack on the ability of children to concentrate at school. Physiol Behav. 2007;90(2-3):382-85.

3. Benton D, Slater O, Donohoe R.T. The influence of breakfast and a snack on physiological functioning. Physiol Behav. 2001;74(4-5):559-71.

4. Pollitt E. Does breakfast make a difference in school? J Am Dietetic Ass. 1995;95(10):1134-39.

5. Pollitt E, Cueto S, Jacoby ER. Fasting and cognition in well- and undernourished schoolchildren: a review of three experimental studies. Am J Clin Nutr. 1998;67(4):779-84. 6. Wesnes KA, Pincock C, Richardson D, Helm G, Hails S. Breakfast reduces declines in attention and memory over the morning in schoolchildren. Appetite. 2003;41(3):329-31. 7. Liu J, Hwang WT, Dickerman B, Compher C. Regular breakfast is associated with increased IQ in kindergarten children. Early Hum Dev. 2013;89(4):257-62.

8. Taki Y, Hashizume H, Sassa Y, Takeuchi H, Asano M, Asano K, et al. Breakfast staple types affect brain gray matter volume and cognitive function in healthy children. PLoS. 2010;5(12):e15213.

9. Logothetis NK. What we can do and what we cannot do with fMRI. Nature. 2008;453(7197):869-78.

10. Francis ST, Head K, Morris PG, Macdonald IA. The effect of flavanol-rich cocoa on the fMRI response to a cognitive task in healthy young people. J Cardiovasc Pharmacol. 2006;47(Suppl 2):S215-20. 
11. Akitsuki Y, Nakawaga S, Sugiura M, Kawashima R. Nutritional quality of breakfast affects cognitive function: An fMRI study. Neuroscience \& Medicine 2011;2:192-97. 12. Liu Y, Gao JH, Liu HL, Fox PT. The temporal response of the brain after eating revealed by functional MRI. Nature. 2000;405(6790):1058-62.

13. Wilke M, Holland SK, Myseros JS, Schmithorst VJ, Ball WS. Functional magnetic resonance imaging in pediatrics. Neuropediatrics. 2003;34(5):225-33.

14. Griffiths ST, Gundersen H, Neto E, Elgen I, Markestad T, Aukland SM, et al. fMRI: blood oxygen level-dependent activation during a working memory-selective attention task in children born extremely preterm. Pediatr Res. 2013;74(2):196-205.

15. Wang S, Yang Y, Xing W, Chen J, Liu C, Luo X. Altered neural circuits related to sustained attention and executive control in children with ADHD: An event related fMRI study. Clin Neurophysiol. 2013;124(11):2181-90.

16. Durlach PJ, Edmunds R, Howard L, Tipper S. A rapid effect of caffeinated beverages on two choice reaction time tasks. Nutr Neurosci. 2002;5(6):433-42.

17. Jaeggi SM, Seewer R, Nirkko AC, Eckstein D, Schroth G, Groner R et al. Does excessive memory load attenuate activation in the prefrontal cortex? Load-dependent processing in single and dual tasks: functional magnetic resonance imaging study. Neuroimage. 2003;19(2 Pt 1):210-25.

18. Cooper SB, Bandelow S, Nevill ME. Breakfast consumption and cognitive function in adolescent schoolchildren. Physiol Behav. 2011;103(5):431-39.

19. Cooper SB, Bandelow S, Nute ML, Morris JG, Nevill ME. Breakfast glycaemic index and cognitive function in adolescent school children. Br J Nutr. 2011;107(12):1823-32.

20. Picton T, Stuss DT, Alexander MP, Shallice T, Binns MA, Gillingham S. Effects of Focal Frontal Lesions on Response Inhibition. Cereb Cortex. 1995;17(4):826-38. 
21. Winterer G, Mulert C, Mientus S, Gallinat J, Schlattmann P, Dorn H, et al. P300 and LORETA: Comparison of Normal Subjects and Schizophrenic Patients. Brain Topogr. 2001;13(4):299-313.

22. Owen AM, McMillan KM, Laird AR, Bullmore E. N-Back Working Memory Paradigm: A Meta-Analysis of Normative Functional Neuroimaging Studies. Hum Brain Mapp. 2005;25(1):46-59.

23. Gibson EL, Green MW. Nutritional influences on cognitive function: mechanisms of susceptibility. Nutrition Research Reviews. 2002;15:169-206.

24. Benton D, Brett V, Brain PF. Glucose improves attention and reaction to frustration in children. Biol Psychol. 1987;24(2):95-100.

25. Benton D, Owens DS (1993). Blood glucose and human memory. Psychopharmacology. $1993 ; 113(1): 83-8$.

26. Benton D, Owens DS, Parker PY. Blood glucose influences memory and attention in young adults. Neuropsychologia. 1994;32(5):595-607.

27. Foster JK, Lidder PG, Sünram SI. Glucose and memory: Fractionation of enhancement effects. Psychopharmacology. 1998;137(3):259-70.

28. Fischer K, Colombani PC, Langhans W, Wenk C. Carbohydrate to protein ration in food and cognitive performance in the morning. Physiol Behav. 2002;75(3):411-23. 


\section{Figure Legend}

Figure 1. fMRI scan of the of the brain showing areas of increased activation linked to the decision reaction test for the breakfast trial relative to the fasted state, specifically within Brodmann 6 area.

Figure 2. fMRI scan of the of the brain showing areas of increased activation linked to the Nback 1 (green) and 2 (red) tasks for the breakfast trial relative to the fasted state, corresponding to Brodmann areas 17 and 45. 


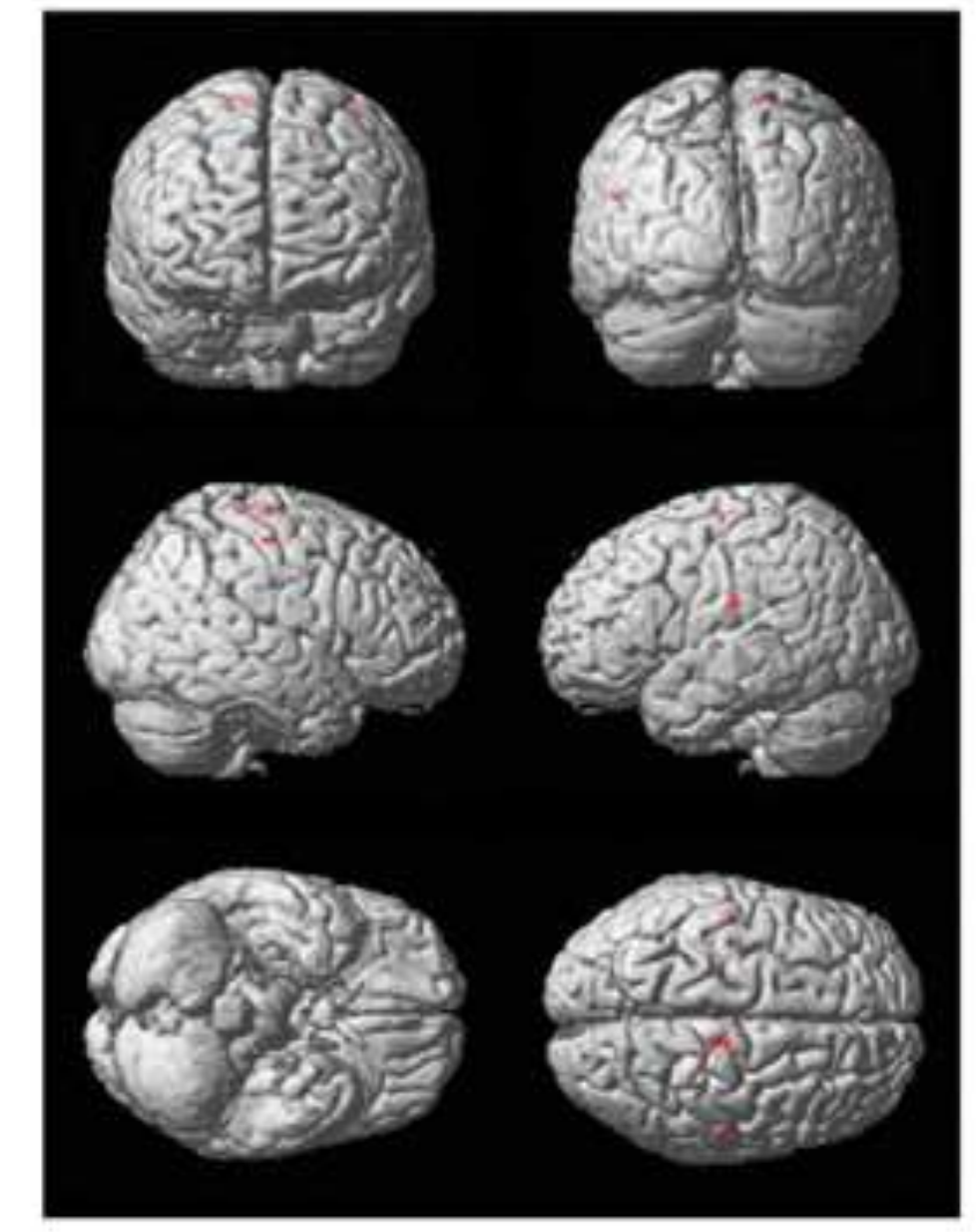

\section{Figure 1.}




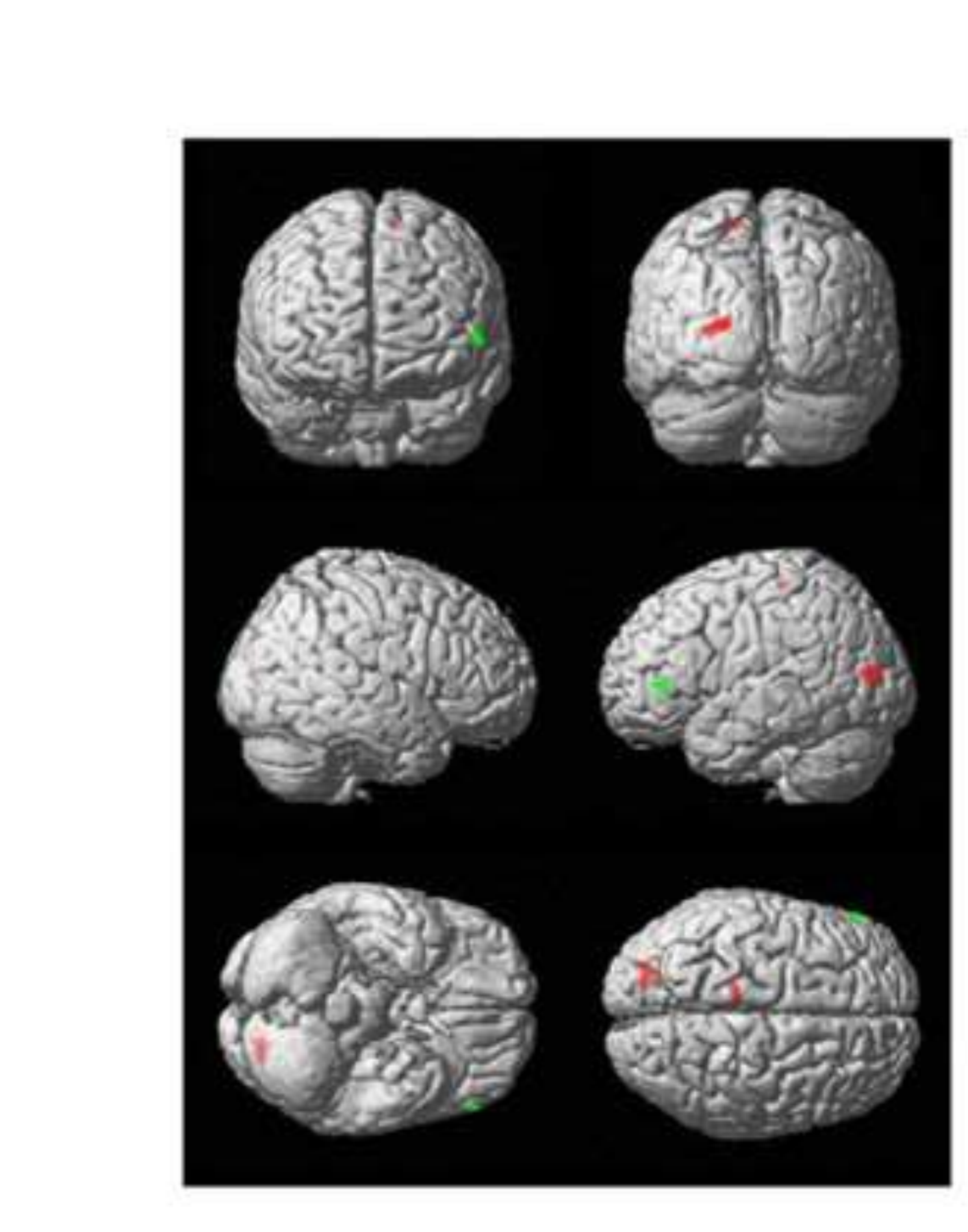

Figure 2.

\section{Figure 2. \\ Figure 2.}

ran 